\title{
Factors Affecting the Price of Commercial Housing in Haikou Housing
}

\author{
Ji-Yan $\mathrm{Wu}^{1}$, Wan-Yin Zheng ${ }^{1} \&$ Xu-You Zeng ${ }^{2}$ \\ ${ }^{1}$ Finance Department of International Business School, Jinan University, Zhuhai, China \\ ${ }^{2}$ Institute for Economic and Social Research, Jinan University, Guangzhou, China \\ Correspondence: Ji-Yan Wu, Finance Department of International Business School, Jinan University, Qianshan Road \\ 206\#, Zhuhai City, Guangdong Province, Post No.519070, China.
}

\author{
Received: July 29, $2018 \quad$ Accepted: August 20, $2018 \quad$ Available online: August 20, 2018 \\ doi:10.11114/aef.v5i5.3491 \\ URL: https://doi.org/10.11114/aef.v5i5.3491
}

\begin{abstract}
This paper uses the grey correlation degree and factor analysis method to carry out empirical research on the main influencing factors of residential price extraction in Haikou City according to the data of Haikou City from 2013 to 2018 as a sample. The research results show that the factors affecting housing prices can be divided into two aspects. From the economic level, the impact of population, regional GDP and per capita disposable income are positive effects. They promote economic growth to increase housing prices. From the perspective of expenditure levels, expected housing prices, investment costs, and consumer price index will affect housing prices by influencing consumers and investors spending decisions. On the whole, the key factors affecting house prices are mainly policies, population movements, economic growth, and total investment costs.
\end{abstract}

Keywords: gray correlation degree, factor analysis, residential property price

\section{Introduction}

\subsection{Background Description}

Housing prices are a "barometer" for the operation of the real estate industry. In the past two decades, since the implementation of the housing reform policy in 1998, China has gradually phased out welfare housing and began to promote housing marketization, for which real estate prices continue to rise. China is experiencing a period of rapid development of urbanization. Every year, there are many laborers entering the city. These new populations will form housing demand for the city where they are located, and drive demand for supporting service facilities and commercial and residential buildings. The price of real estate will increase.

In addition to the residential consumption demand of real estate, there is still huge investment and speculative demand for real estate in China, which also boosted the rise in real estate prices. Due to the lack of diversified investment channels, a large amount of social idle funds flocked to the real estate industry. In the past 10 years, the investment demand of China's real estate has been rising, which has pushed up house prices. It in turn has led to an increase in investment demand, which has contributed to an accelerated cycle of rising house prices and rising investment demand.

\section{Related Literature Review}

Real estate is a very hot topic in China. The rapid development of Hainan's economy in recent years has brought great impact to the real estate industry. Many domestic scholars have studied the factors affecting real estate prices, and the research results are quite abundant.

Cui Cheng-ying (Cui C.Y.,2011) combined consumers, real estate developers and the government as the starting point to study the main influencing factors of housing prices. The results show that when the price increase exceeds the level of economic growth, the government's financial support becomes the fundamental factor for housing prices. Zhao Li-li, Jiao Ji-wen (Zhao L.L.\&Jiao J.W.,2007) introduced the indicator system from both supply and demand and used the grey correlation analysis method. The results show that the large demand for real estate leads to the imbalance of supply and demand structure, which contributes to the continuous rise of housing prices. Resorting both to a non-parametric approach and a discrete-choice model, Vladimir Borgy, Laurent Clerc and Jean-Paul Renne(Vladimir Borgy\&Laurent Clerc\&Jean-Paul Renne,2010) analyzed the abilityof a set of indicators to robustly explain costly house price booms. According to the results, real long term interest rates, total investment, real credit and real stock prices tend to increase 
the probability of a costly house price boom. Qian Jing, Hao Yi-bo (Qian J.\& Hao Y.B.,2017) used the analysis of variance of VAR model, which is concluded that fixed asset investment and per capita disposable income have a significant role in promoting housing prices. Cheng Huiru (Cheng H.R.,2016) analyzed the impact of monetary policy tools on China's housing prices. The expansionary monetary policy's pulling effect on housing prices is far greater than the tightening monetary policy's restraining effect on housing prices. The money supply represents the quantitative monetary policy tool's regulation of house prices is stronger than the price-based monetary policy tools represented by interest rates. Lu Wei (Lu W.,2014) derived the real estate price from the financial factors such as the interest rate and exchange rate as a result of the long-term effects of many financial and institutional factors. Xu Zan (Xu Z.,2014) used the regression model to analyze the price of commercial housing from the perspective of real estate, which is concluded that the real estate tax and fee policy is finally passed on to consumers as part of the housing price. Geng Li-juan (Geng L.J.,2013) pointed out the influence of market and government factors on housing prices. Due to the concealment of government policy regulation, it is necessary to play the role of the government's "tangible hand" and broaden the field of vision of the housing price determination mechanism.

It can be seen that the factors affecting real estate prices can be analyzed from different angles, and the conclusions obtained are also inconsistent. But it is all about supply and demand, policies and markets, real estate market participants, financial factors, and so on. This paper studies the economic level and expenditure level to explore the factors affecting housing prices.

\section{Research Design}

\subsection{Analysis of the Current Situation of Housing Market in Haikou City}

As the capital city of Hainan Province, Haikou City is also a famous tourist attraction, so the development of the real estate industry started earlier. Since the establishment of the Hainan Special Economic Zone in 1988, the price of commercial housing in Hainan has risen sharply within five years. In 2010, the "Hainan International Tourism Island Construction and Development Plan" was approved, which doubled the price of commercial housing. On April 13, 2018, after the introduction of the major policy of the construction of the Free Trade Zone (Hong Kong) in Hainan Island, the price of commercial housing in Haikou rose by 500 yuan to 1,000 yuan per square meter every day. On the evening of April 22, 2018, the purchase restriction policy was introduced and the implementation of global restrictions on purchases tries to control the upward trend in housing prices.

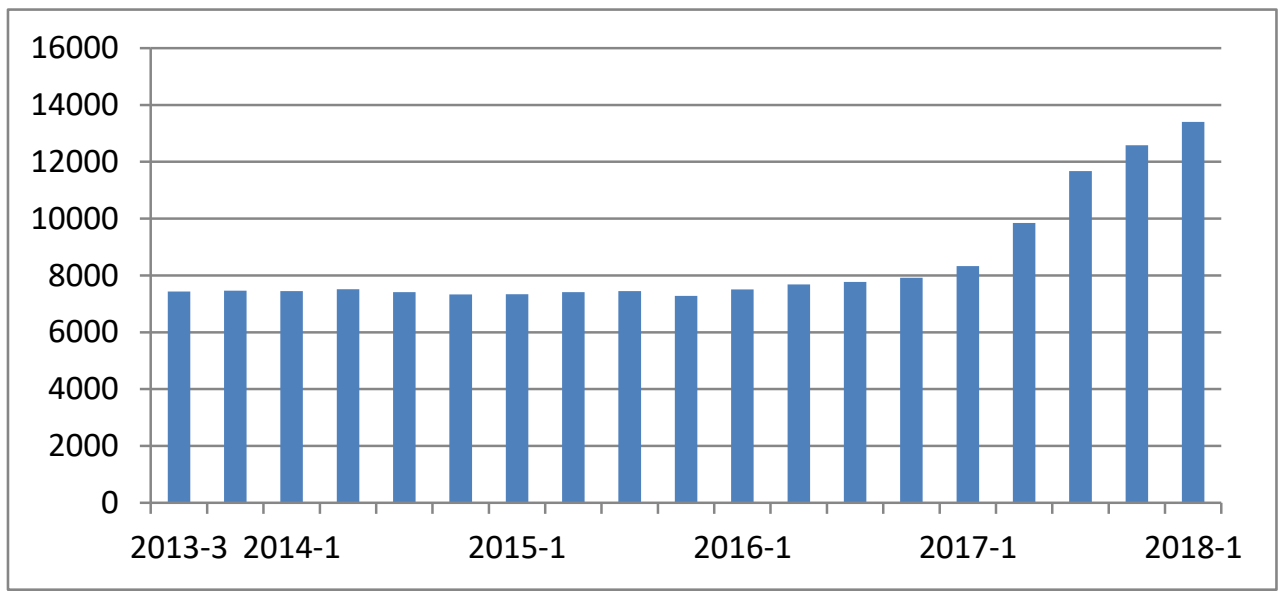

Figure 1. Haikou City's housing price trend chart for the past five years

\subsection{Research on the Factors Affecting Housing Price in Haikou City}

There are many factors affecting housing prices. The representative of Haikou City, the factors affecting housing prices can be divided into economic factors, social factors, political factors, etc. Through the qualitative and quantitative analysis of specific influencing factors, we find out the most important factors affecting housing prices to verify its correlation, analyzing the future trend of housing prices under different conditions and policies, and give pertinent comments and suggestions.

\subsection{Data Collection and Processing}

Data are collected and tested for accuracy and completeness. Through the Haikou City Statistical Yearbook, Hainan Statistical Yearbook, and China's land price information service platform, we collected and analyzed monthly data on housing prices, regional GDP, investment costs, population data, expected prices, per capita disposable income and consumer price index (CPI) in Haikou City in the past five years. 


\section{Theory and Model Preparation}

\subsection{Comparison Model of Grey Relational Analysis}

The basic idea of the grey correlation analysis method is to judge whether the connection is close according to the similarity degree of the sequence curve geometry. The closer the curve is, the greater the degree of association between the corresponding sequences. It transforms the evaluation problem into the degree of relevance. The parent sequence is defined according to certain criteria. The degree of association between each subsequence (comparative sequence) and the parent sequence is calculated, and the comprehensive evaluation results are obtained by sorting and comparing. For the purpose of analyzing the difference in this question, the difference between the two is judged by calculating the degree of correlation between the two.

Advantages of the gray model:

(1) There is no need to have a large number of samples;

(2) The results of quantitative analysis are not inconsistent with the results of qualitative analysis;

(3) It can be used for short-term and medium-term forecasts.

Step 1 Select the comparison sequence

According to the condition of the subject, the matrix $\mathrm{H}$ is defined, and the element $h_{i}$ represents the influence of the $i^{t h}$ principal component on the house price. With housing price as the parent sequence, $\mathrm{i}=1,2,3, \mathrm{k}=1,2,3, \ldots, 60$, which is:

$$
\mathrm{h}_{\mathrm{i}}=\frac{1}{60} \sum_{\mathrm{n}=1}^{60} \mathrm{q}_{\mathrm{nk}}
$$

Among them, $q_{n k}$ represents the price of the $k^{t h}$ month of the $i^{\text {th }}$ principal component (May 2013 to April 2018).

Step 2 Calculate the relevance

The correlation coefficient between the subsequence and the corresponding number of the parent sequence can be calculated by the following formula:

$$
\mathrm{v}_{\mathrm{i}}(\mathrm{j})=\frac{\mathrm{a}+\rho \cdot \mathrm{b}}{\Delta_{\mathrm{i}}(\mathrm{j})+\rho \cdot \mathrm{b}}
$$

Where, $a=\min \min \left\{\Delta_{i}(j)\right\}, b=\max \max \left\{\Delta_{i}(j)\right\}, \rho=0.5, \Delta_{i}(j)=\left|h_{i j}-h_{1 j}\right|$;

By averaging the correlation coefficients, the corresponding correlation degree is obtained as follows:

$$
u_{i}=\frac{1}{60} \sum_{j=1}^{60} v_{i}(j)
$$

The degree of relevance indicates how much the main influencing factors are related to the price of the property.

\subsection{Factor Analysis}

Step 1 Data standardization processing

The $j^{\text {th }}$ indicator of the influencing factor of the $i^{\text {th }}$ house price is $x_{i j}$, and each indicator is converted into a standard indicator $x_{i j}^{\prime}$. The formula is:

$$
\begin{gathered}
u_{j}=\frac{1}{n} \sum_{i=1}^{n} x_{i j} \\
\sqrt{s_{j}}=\sqrt{\frac{1}{n-1} \sum_{i=1}^{n}\left(x_{i j}-\mu_{j}\right)^{2}}, \quad(j=1,2, \ldots, m)
\end{gathered}
$$

$u_{j}, \sqrt{s_{j}}$ is the mean of the influencing factors and the standard deviation of the influencing factors of the $j^{\text {th }}$ indicator.

The following formula is a standardized indicator variable:

$$
x_{i j}^{\prime}=\frac{x_{i j}-u_{j}}{\sqrt{s_{j}}}, \quad(i=1,2, \ldots, m)
$$


$u_{j}$ represents the $j^{\text {th }}$ indicator mean value, and $\sqrt{s_{j}}$ represents the $j^{\text {th }}$ indicator standard deviation.

Step 2 Data inspection

The data analysis software SPSS is used to test the correlation of the standardized indicators, namely the Bartlett sphericity test and the KMD test. According to the test result, we judge whether the index is suitable for factor analysis. If the value of the Bartlett sphericity test sig (the $\mathrm{P}$ value) is less than 0.05 and the value of KMD more than 0.5, it can be used for factor analysis. The closer the value is to 1 , the more suitable for factor analysis.

Step 3 Factor extraction (Principal Component Analysis)

(1) Calculate the correlation coefficient matrix $R$

Correlation coefficient matrix $\mathrm{R}=\left(\mathrm{r}_{\mathrm{ij}}\right)_{\mathrm{m} \times \mathrm{m}}$

$$
\mathrm{r}_{\mathrm{ij}}=\frac{\sum_{\mathrm{k}=1}^{\mathrm{n}} \mathrm{x}_{\mathrm{ki}}^{\prime} \cdot \mathrm{x}_{\mathrm{kj}}^{\prime}}{\mathrm{n}-1}
$$

$\mathrm{r}_{\mathrm{ij}}=1, \mathrm{r}_{\mathrm{ij}}=\mathrm{r}_{\mathrm{ji}}, \mathrm{r}_{\mathrm{ij}}$ is the correlation coefficient between the $\mathrm{i}^{\text {th }}$ index and the $j^{\text {th }}$ index.

(2) Calculate eigenvalues and eigenvectors

Calculate the eigenvalues of the correlation coefficient matrix R: $\lambda_{1} \geq \lambda_{2} \geq \cdots \geq \lambda_{m} \geq 0$, and its corresponding feature vector: $\mu_{1}, \mu_{2}, \ldots, \mu_{\mathrm{m}}$

$\mu_{\mathrm{j}}=\left(\mu_{1 \mathrm{j}}, \mu_{2 \mathrm{j}}, \ldots, \mu_{\mathrm{mj}}\right)^{\mathrm{T}}$ is $\mathrm{m}$ new index variables composed of feature vectors.

$$
\left\{\begin{array}{c}
\mathrm{y}_{1}=\mu_{11} \overline{\mathrm{x}_{1}}+\mu_{21} \overline{\mathrm{x}_{2}}+\cdots+\mu_{\mathrm{m} 1} \overline{\mathrm{x}_{\mathrm{m}}} \\
\mathrm{y}_{2}=\mu_{12} \overline{\mathrm{x}_{1}}+\mu_{22} \overline{\mathrm{x}_{2}}+\cdots+\mu_{\mathrm{m} 2} \overline{\mathrm{x}_{\mathrm{m}}} \\
\cdots \cdots \cdots \cdots \cdots \cdots \cdots \cdots \cdots \cdots \cdots \cdots \cdots \cdots \cdots \cdots \cdots \cdots \cdots \cdots \cdots \cdots \cdots \cdots \cdots \\
\mathrm{y}_{\mathrm{m}}=\mu_{1 \mathrm{~m}} \overline{\mathrm{x}_{1}}+\mu_{2 \mathrm{~m}} \overline{\mathrm{x}_{2}}+\cdots+\mu_{\mathrm{mm}} \overline{\mathrm{x}_{\mathrm{m}}}
\end{array}\right.
$$

Where $\mathrm{y}_{1}$ is the first principal component, $\mathrm{y}_{2}$ is the second principal component, ..., $\mathrm{y}_{\mathrm{m}}$ is the $m^{\text {th }}$ principal component.

Each factor corresponds to an eigenvalue and an eigenvector. The eigenvalue reflects the contribution rate of the factor pair to all indicators, and the eigenvector is the coefficient of the linear relationship between the normalization factor and each standardized index.

(3) Calculate the variance contribution rate and the cumulative contribution rate of the eigenvalue $\lambda_{j}(j=1,2, \ldots, m)$.

The variance contribution rate of the principal component $y_{j}$ is:

$$
b_{j}=\frac{\lambda_{j}}{\sum_{k=1}^{m} \lambda_{k}}(j=1,2, \ldots, m)
$$

Cumulative contribution rate of principal component is:

$$
y_{1}, y_{2}, \ldots, y_{p} \alpha=\sum_{j=1}^{p} b_{j}
$$

When the feature value is less than 1 or the cumulative contribution rate is greater than $85 \%$, the first $\mathrm{p}$ index variables $\mathrm{y}_{1}, \mathrm{y}_{2}, \ldots, \mathrm{y}_{\mathrm{p}}$ are selected as $\mathrm{p}$ principal components, instead of the original $\mathrm{m}$ index variables. So that the $\mathrm{p}$ principal components can be comprehensive analyzed. The general formula is as follows:

$$
\mathrm{M}=\sum_{\mathrm{j}=1}^{\mathrm{p}} \mathrm{b}_{\mathrm{j}} \mathrm{y}_{\mathrm{j}}
$$

Where $b_{j}$ is the variance contribution rate of the $j^{\text {th }}$ principal component, and can be evaluated based on the comprehensive scores.

Step 4 Factor analysis

Screening with eigenvalues less than 1, two principal factors can be obtained according to the linear relationship between the principal factor and the variables, which contain most of the information about the original variables. The two main factors affecting house prices are explained and named separately.

Step 5 Factor rotation 
According to the load relationship between the principal factor and the variable, it is difficult to obtain the explanation of the principal factor from the related literature. Factor rotation can be used to change the load relationship between the factor and the variable, so that the factor has a more explicit explanation. In this paper, the maximum orthogonal rotation method is used to achieve the factor rotation, and the step is implemented by SPSS software.

\section{Analysis of Results}

\subsection{Gray Correlation}

Table 1. Gray correlation between house prices and various factors

\begin{tabular}{l|lllllll}
\hline & $\begin{array}{l}\text { Regional } \\
\text { GDP }\end{array}$ & $\begin{array}{l}\text { Population } \\
\text { Quantity }\end{array}$ & $\begin{array}{l}\text { Investment } \\
\text { Cost }\end{array}$ & $\begin{array}{l}\text { Expected } \\
\text { Price }\end{array}$ & House & $\begin{array}{l}\text { Per capita disposable } \\
\text { Income }\end{array}$ & CPI \\
\hline $\begin{array}{l}\text { House } \\
\text { price }\end{array}$ & 0.6647 & 0.8202 & 0.5871 & 0.8681 & 0.726 & 0.835 \\
\hline
\end{tabular}

It can be seen from Table 1 that the correlation between house prices and population, expected house prices, CPI and disposable income is strong, and the correlation between investment cost and regional GDP is generally seen. It can be seen that the impact of housing prices on consumption sector is higher. The impact on housing prices in the production sector is not large enough.

In combination with the introduction of Hainan's policies, we understand that the introduction of a free trade zone and a policy of restricting purchases has a huge impact on consumer spending decisions in the consumer sector. The increased housing prices are mainly due to increased demand for demand of the real estate is larger than supply in the market. The pressure to cause price increases. The policy has little impact on producers and investors on the production sector, resulting in an imbalance between supply and demand.

Because the gray correlation degree has low requirements on data, subjectivity is too strong, the data cannot be analyzed objectively. For the independent variables, the correlation between the independent variables cannot be well excluded. Therefore, we use factor analysis to find potential common factors from the variables and study the relationship between the interpreted variables and the common factors through this representative factor.

\subsection{Factor Analysis Results}

Because there are many factors affecting housing prices, involving economic, social, and policy aspects, we use factor analysis to extract the most important influencing factors through principal component analysis, and empirically analyze the impact of major influencing factors on housing prices. In this paper, SPSS software is used for factor analysis, using the maximum variance method and orthogonal rotation method, and finally the Bartlett sphericity test and KMD test.

Table 2. Bartlett Sphericity test and test results

\begin{tabular}{lll}
\hline KMO & & 0.65 \\
\hline Bartlett sphericity test & Approximate Chi-square & 93.983 \\
& Degree of freedom & 21 \\
& significance & 0.000 \\
\hline
\end{tabular}

The test is used to check whether the partial correlation coefficient between variables is too small. The closer to 1 , the better the test effect. If it is less than 0.5 , the factor analysis is not applicable. It can be seen from Table 2 that the KMD value is 0.65 , indicating that it is suitable for factor analysis. The sphericity test is used to check whether the correlation coefficient matrix is an identity matrix. If the null hypothesis is rejected, it means that the variables are independent of each other. A significant result of 0.000 indicates rejection of the null hypothesis.

Table 3. Explanation of variance

\begin{tabular}{llll}
\hline Common factor & Initial eigenvalue & Percentage of variance (\%) & Cumulative contribution rate (\%) \\
\hline $\mathrm{F}_{1}$ & 4.13 & 59.003 & 59.003 \\
$\mathrm{~F}_{2}$ & 1.15 & 16.434 & 75.438 \\
\hline
\end{tabular}

According to the results in Table 3, the cumulative variance contribution rate of F1 and F2 reaches 75.438\%, which means that two factors can be used as a common factor to interpret the raw data. According to the linear relationship between the main factor and the variable, two main factors are obtained, which contain most of the information of the original variable. The two main factors affecting the house price are explained separately. According to the relevant literature and economic knowledge, the first principal component is named 'economic level' and the second principal component is named 'expenditure level'. 
Table 4. Component matrix after rotation

\begin{tabular}{lll}
\hline & $\mathrm{F}_{1}$ & $\mathrm{~F}_{2}$ \\
\hline Supply price & 0.735 & 0.568 \\
Demand price & 0.766 & 0.484 \\
GDP in Haikou & 0.86 & 0.022 \\
Per capita disposable income & 0.696 & -0.05 \\
CPI & -0.102 & 0.884 \\
Total investment cost & 0.814 & -0.013 \\
population & 0.955 & 0.07 \\
\hline
\end{tabular}

Since F1 has the largest contribution rate of variance, it relies on the data of F1 to judge the degree of influence of various factors on house prices. According to Table 4, the degree of influence of each variable on the residential price of Haikou City is: population > Haikou GDP > total investment cost > demand price > supply price > per capita disposable income $>$ CPI

The results show that the main factors that have a significant impact on the price of commercial housing in Haikou are population, Haikou GDP, total investment cost, expected housing prices, supply prices, and per capita disposable income.

It can be concluded from Table 4 that the introduction of Hainan's policies has led to the flow of talents to Haikou City and the regional GDP has been increasing, which has increased the overall investment level of the real estate industry, raising the economic level and affecting the continuous rise in housing prices. Other factors have also contributed to the rise in housing prices.

\subsection{Quantitative Analysis of Major Factors}

(1) Quantitative analysis of population: Through the factor analysis model, using the population of each quarter from 2013 to 2018, it can be seen the influence from the rotated component matrix. On the one hand, the inflow of talents will drive the GDP growth of Haikou and promote economic growth. On the other hand, the increase in population will increase the demand for real estate, resulting in a shortage of supply. Therefore, the flow of talents and population growth affects the price of commercial housing to a large extent and is positively correlated with the price of commercial housing.

(2) Quantitative analysis of Haikou's GDP: According to the factor analysis model, Haikou's GDP growth drives the economic growth of the entire city of Haikou, which will increase the income level of residents and cause housing price increases. Therefore, Haikou GDP and commercial housing price is positively correlated.

(3) Quantitative analysis of the total cost of investment: The investment cost refers to the total capital used for the development of commercial housing. According to the factor analysis model, the investment of the real estate industry by the government, developers and investors will increase the total cost of investment. Pushing up house prices. Therefore, the investment cost is positively correlated with the price of commercial housing.

\subsection{Qualitative Analysis}

(1) Policy: The resolution on the establishment of the Hainan Special Economic Zone on April 13, 1988 caused the price of commercial housing in Hainan to rise sharply within five years. In 2010, the "Hainan International Tourism Island Construction and Development Plan" was approved, which doubled the price of commercial housing. On April 13, 2018, after the introduction of the major policy of the construction of the Free Trade Zone (Hong Kong) in Hainan Island, the price of commercial housing in Haikou rose by 500 yuan to 1,000 yuan per square meter every day. The price of commercial housing in Sanya rose from 3,000 yuan to 8,000 yuan. On the evening of April 22, 2018, a purchase restriction policy was introduced and a global purchase restriction was implemented. It can be seen that the policy has a great impact on the impact of housing prices. The introduction of policies affects housing prices by affecting the direction of producer investment in the real estate market and consumer spending decisions. For example, the policies that promote economic growth and talent inflows will lead to rising housing prices. The restrictions on purchases and tax increases will curb housing price growth. The monetary policy will also guide the flow of funds and affect housing prices. The policy is an "invisible hand", and constantly changes the relationship between supply and demand in the real estate market, which has a great impact on housing prices.

(2) Environmental factors: Haikou belongs to the tourist city and is also the capital city of Hainan Province. Therefore, environmental factors are a relatively important factor. The better the environment is, the closer it is to tourist attractions. The greater the positive effect of the environment on the price of commercial housing, and the higher the price of the property is. 


\section{Suggestions}

Based on the empirical research in this paper, it shows that the main economic factors affect commodity housing prices in Haikou are: population, Haikou GDP, and total investment cost. In addition to economic factors, policy factors and environmental factors also account for a large proportion. In order to better promote the healthy and sustainable development of the real estate market, we make the following recommendations:

(1) Adjust the supply and demand structure of the property. In the study of this paper, population growth, GDP growth, and per capita disposable income are undoubtedly the main reasons for increasing the demand for civilian housing in Haikou City. The total investment cost and expected housing price are the main factors for the supply of commercial housing in Haikou. With the development of urbanization, Haikou City will face more and more population demand, the demand for commercial housing is also increasing. The economic development is getting faster and faster and the income level is increasing, wherefore the increase of housing prices has become an inevitable trend. Therefore, in terms of supply of commercial housing, the government should increase security in the rapid development of affordable housing, accelerate the construction of economical commodity housing, and appropriately expand residential land. Through the above, the government can ensure supply and maintain the balance between demand and supply of commercial housing in the real estate industry.

(2) Continue to adjust policies and grasp the direction of the commodity housing market. Government policy is a very important factor for commercial housing, and it is also difficult to estimate. For the rise and fall of commercial housing prices, it is difficult to maintain the healthy and sustainable development of commercial housing by relying solely on market regulation. At this time, it is necessary to rely on the regulation of government policies. The government's policy should be closely related to the status of the city, fully consider the urban economic structure, population and income level of residents. Furthermore, the government should grasp the direction of market regulation and consider the heterogeneity of the market to control the house price in a reasonable fluctuation. The policies should promote the healthier development of housing prices and improve people's happiness.

(3) Strictly restrict speculative purchases. Faced with the pressure of rising house prices, the government should better grasp the supervision, considering the interests of different levels of housing consumption, especially, it is very important to provide economic security measures for low-income families. At the same time, it is also necessary to speed up urban planning in Haikou City which aims to form an obvious commercial center and accelerate infrastructure construction.

(4) Strengthen housing consumption management. The government should properly balance the resources of each region, guide the expectation of consumers' commodity housing price and consumer attitude actively, which can promote the healthy development of the real estate market. The government must not only increase the degree of controlling the risk, but also strengthen the promotion and education of economic knowledge.

\section{References}

Cheng, H. R. (2016). Currency factor Asymmetry study of the impact of housing prices, Zhejiang Finance, (01), 40-45.

Cheng, Q. L. (2014). An Empirical Study on the Factors Affecting China's Housing Price Rise, Electronic Production, 2014(06), 268-269.

Cui, C. Y. (2011). An Empirical Study on the Factors Affecting Commodity Price in Beijing, Productivity Research, (09), $78-80+132$.

Geng, L. J. (2013). Government Behavior and Market Factors Behind House Price: A Literature Review, SAR Economy, (12), 103-104.

Huang, H. X., \& Hou, L. Y. (2011). Summary of Factors Affecting Housing Prices, China Real Estate, (07), 39-44.

Li, S. H. (2012). Research on the relationship between urban land price and commercial housing price in China, Nankai University, (05), 171-172.

Liu, W., \& Yu, Q. T., \& Gao, Q. Q. (2012). Research on Factors Affecting China's Housing Price Based on Simultaneous Equation Model, Wuhan University of Technology, (02), 123-126.

Liu, Y. Y., \& Guo, Q. (2016). Analysis of Factors Affecting Housing Price in Guizhou Province Based on Regression Model, Modern Economic Information, (10), 497.

Lu, W. (2014). Theoretical and Empirical Analysis of the Impact of Financial Factors on China's Housing Price, Capital University of Economics and Business, (03), 54.

Qian, J., \& Hao, Y. B. (2017). Reason Analysis and Regulation Policy Design of High Housing Price in Nanchang City__An Empirical Study Based on VAR Model, Financial Economy, (07), 158-159. 
Tong, C. J., \& Yang, H. L. (2007). Research on the Factors Affecting Real Estate Price, Construction Economy, (S1),190-192.

Vladimir, B., Laurent, C., \& Jean, P. R. (2010). House price Boom/Bust Cycles: Identification Issues and Macro-prudential Implications, Housing Markets in Europe, (2010), 359-383.

Xiong, Y. (2009). Research on the Factors Affecting Real Estate Price in China, Financial Economy, (01), 35-37.

$\mathrm{Xu}, \mathrm{Z}$. (2014). Analysis of the impact of cost factors on commodity housing prices, Market Weekly (theoretical research), (02), 28-29+73.

Yang, W. (2008). Analysis of the social reasons for the rapid rise of China's housing prices, Jilin University, (04), 29-33.

Zhao, L. L., \& Jiao, J. W. (2007). Grey Correlation Analysis of House Price Influencing Factors, Statistics and Decision, (12), 74-75.

\section{Copyrights}

Copyright for this article is retained by the author(s), with first publication rights granted to the journal.

This is an open-access article distributed under the terms and conditions of the Creative Commons Attribution license which permits unrestricted use, distribution, and reproduction in any medium, provided the original work is properly cited. 